\title{
Towards a Circular Economy Taxation Framework: Expectations and Challenges of Implementation
}

\author{
Leonidas Milios ${ }^{1}$
}

Received: 20 October 2020 / Accepted: 22 December 2020/Published online: 21 January 2021

(C) The Author(s) 2021

\begin{abstract}
The transition to a circular economy is a complex process requiring wide multi-level and multi-stakeholder engagement and can be facilitated by appropriate policy interventions. Taking stock of the importance of a well-balanced policy mix that includes a variety of complementing policy instruments, the circular economy action plan of the European Union (COM(2020) 98 final) includes a section about "getting the economics right" in which it encourages the application of economic instruments. This contribution presents a comprehensive taxation framework, applied across the life cycle of products. The framework includes (1) a raw material resource tax, (2) reuse/repair tax relief, and (3) a waste hierarchy tax at the end of life of products. The research is based on a mixed method approach, using different sources to analyse the different measures in the framework. More mature concepts, such as material resource taxes, are analysed by reviewing the existing literature. The analysis of tax relief on repairs is based on interviews with stakeholders in Sweden, where this economic policy instrument has been implemented since 2017. Finally, for the waste hierarchy tax, which is a novel proposition in this contribution, macroeconomic modelling is used to analyse potential impacts of future implementation. In all cases, several implementation challenges are identified, and potential solutions are discussed according to literature and empirical sources. Further research is required both at the individual instrument and at the framework level. Each of the tax proposals needs a more detailed examination for its specificities of implementation, following the results of this study.
\end{abstract}

Keywords Circulareconomy $\cdot$ Economic policy instruments $\cdot$ Resource tax $\cdot$ Resource efficiency $\cdot$ Waste tax

Leonidas Milios

leonidas.milios@iiiee.lu.se

1 International Institute for Industrial Environmental Economics, Lund University, P.O. Box 196, 22100 Lund, Sweden 


\section{Introduction}

Over the last decades, a continuously expanding global economy has put stress on the earth's natural resources, raising concerns about increasing adverse environmental impacts and impending resource shortages [1]. To mitigate the potential overexploitation of resources and the associated environmental damage, the promotion of circular material use (including the reduction of material input, as well as reuse and recycling) is necessary for reducing the generation of waste and the economy's dependence on the extraction of primary raw materials $[2,3]$.

National governments and supranational governance entities, such as the European Union (EU), are gradually integrating such resource concerns into their policy agendas. The strategic direction of the EU has progressively focused on increasing resource productivity and innovation in the economy, aiming at the efficient and effective use of resources, sustained economic growth and job creation, with less environmental impact [4]. One of the basic premises of the recently proposed 'Green Deal' for Europe is the promotion of the circular economy [5].

The circular economy (CE) aims at maximising the value and utility of resources and energy within production systems, based on the premise that natural resources are scarce and that products at their end of life (EOL) may retain some value [6]. Having its roots in industrial ecology and environmental economics [6,7], the CE is not a solidly defined concept but follows a few general principles that remain constant in all definitions available in literature. Total material use reduction; reuse of products by extension of product life through repair, refurbishment and remanufacturing; recycling; and recovering materials in production and use processes constitute the basic elements of CE [8]. Moreover, CE is operationalised at multiple levels, the micro level (products, companies, customers), meso level (eco-industrial parks, economic sectors) and macro level (region, nation and beyond) $[6,8]$.

The shift to a circular economy is a complex process requiring a wide multi-level and multistakeholder engagement from all parts of society [9]. Therefore, realising a systemic shift by employing an individual policy instrument may prove to be insufficient. Applying just one policy instrument would most likely change an individual driver, failing to address the issue holistically [10]. Consequently, a more complex approach would be required by developing a mix of policies that targets the multi-faceted aspects of a circular economy transition.

The policy instruments that are available in the arsenal of governments to lay down the enabling conditions for a circular economy can be generally distinguished between three broad categories: administrative (e.g. regulatory bans, standards, targets), economic (e.g. taxes, tariffs, subsidies) and informative (e.g. labels, certifications, information campaigns). These can be of mandatory or voluntary nature $[4,11]$.

To address the CE holistically, the European Commission takes a life-cycle approach in designing policy proposals that target specific aspects of production, consumption and waste management. This is documented in the EU Circular Economy Action Plans (COM(2015) 614 final and $\operatorname{COM}(2020) 98$ final), where several policy instruments at different life-cycle stages are included. So far, the focus was mainly on direct administrative interventions, backed by informative instruments and tools, while the potential of economic instruments for a circular economy was not addressed adequately [4, 12]. Taking stock of the importance of a wellbalanced policy mix that includes a variety of complementing policy instruments, the latest $\mathrm{CE}$ Action Plan (COM(2020) 98 final) includes a section about "getting the economics right" in which it encourages the broader application of economic instruments, such as environmental 
taxation (including waste taxes), and enables EU Member States to use variable value added tax (VAT) rates to promote circular economy activities that target final consumers, notably repair services.

Although environmental taxes are addressed in literature regarding the potential effects on resource savings, e.g. $[13,14]$, in practice the preference of such measures seems to be limited [15]. Material resource taxes internalise the environmental and social externalities of resource extraction [16] but are considered only as second-best policies for addressing resources [17] due to their "inherent impreciseness" [18]. There are multiple structural barriers connected to the design, implementation and administration of resource taxes, as well as information barriers and split incentives between the actors involved. Therefore, resource taxation is "implemented on an exclusively selective basis and cannot be considered as sending a clear-cut signal to economic actors" [18]. Apart from resource taxes, proposed tax reductions for repair services have not been thoroughly assessed for potential effects, as their limited application and tax base so far indicate high administrative costs.

To date, the research related to appropriate policy interventions for a resource efficient CE is limited, and only a handful of articles offers insights to the necessary policy instruments for comprehensive CE policy mixes, e.g. $[10,12,19]$. Moreover, the majority of policy instruments presented in previous research is either administrative or informative in nature, largely disregarding the potential of economic policy instruments to contribute in the CE policy mix. The policy measures either derived from existing policy approaches (e.g. eco-design and green public procurement) or constituted novel propositions for consideration by policymakers (e.g. reuse targets and reuse quality labelling), and fiscal measures in the policy mix played only a minor role.

This contribution aims at complementing previous research by developing a fiscal framework for $\mathrm{CE}$, based on resource, product and waste taxation. The framework is developed independently in this article, but it has the potential to be integrated in existing policy approaches as a supporting (market-based) mechanism. The framework takes into consideration the different life-cycle stages of products, from resource extraction and input to waste disposal — or EOL stage. By following this life-cycle modular approach, the framework is compatible to similar approaches in CE policy development and can be implemented holistically or partially, depending on the life-cycle stage that needs market-based support. Moreover, the objective of the article is not only to introduce the framework but also to scrutinise its potential and analyse the challenges of its implementation.

The overall aim and the objective of this contribution guided the research approach which is formulated in two research questions: (1) How does a fiscal policy framework for CE can be constructed to address resource efficiency in a life-cycle perspective and what instruments would be appropriate to include? (2) What is the potential effectiveness of a fiscal policy framework for CE?

In the following section ("Circular Economy Taxation Framework" section), the Circular Economy Taxation Framework is presented together with the rationale of developing this framework based on literature insights. The "Methodology" section provides an overview of the different methods used to derive the conceptual taxation framework and to analyse the potential and implementation challenges of the different elements of the framework. In the "Results and Discussion" section, the research results are presented and analysed in a comprehensive discussion, and finally the "Conclusions and Future Research" section concludes the paper and provides suggestions for future research. 


\section{Circular Economy Taxation Framework}

The Circular Economy Taxation Framework constitutes a comprehensive fiscal policy approach targeting each of the life-cycle stages of a product with a different policy intervention. The framework includes three life-cycle stages: (1) production, (2) product use and (3) waste management. For each stage, a different taxation approach is used to reflect more accurately the desirable resource efficiency outcome. Figure 1 illustrates the different elements of the framework.

\section{Production Stage of the Life Cycle}

In the production stage, a natural (virgin) raw material resource tax is proposed. Raw material resource taxes can be applied at different stages of the production process: (a) at the stage of extraction of the raw material, (b) at the input of the material at the first industrial use and (c) at the final consumption stage of products with embedded material content [20]. The design of this intervention is not explicitly defined within the proposed framework, leaving room for policy decision-makers to adapt the application of the tax according to the most appropriate circumstances in their respective jurisdictions. The different application approaches are discussed in further detail in the "Results and Discussion" section of this article.

From a public policy perspective, a tax on raw material resources can be motivated by both fiscal and environmental arguments [18]. From an economic point of view, a tax on raw material resources can be motivated either due to a market failure in which market forces are not effectively capturing the associated environmental externalities of resource extraction and use or in the case that other environmental regulations (e.g. pollution mitigation) are not effective in addressing the relevant market failure better than a tax [21]. Further, Söderholm [17] motivates the decision of adopting raw material taxes on (a) concerns of resource depletion, (b) addressing environmental externalities, (c) the expectation of future amounts of emissions or waste (which a tax on raw material inputs could prevent downstream) and (d) a way of encouraging the substitution of virgin material resources with secondary and recycled materials.

Radetzki [22] has demonstrated that demand for raw material resources tends to be ownprice inelastic, especially in the short run. This is partly because there are usually few substitutes to a given resource, and due to the intense extraction and processing of natural resources (e.g. metal smelting), which makes the substitution to other raw material input too costly and time-consuming. Therefore, the application of a tax on primary raw material resources might induce a demand for secondary material resources-where readily

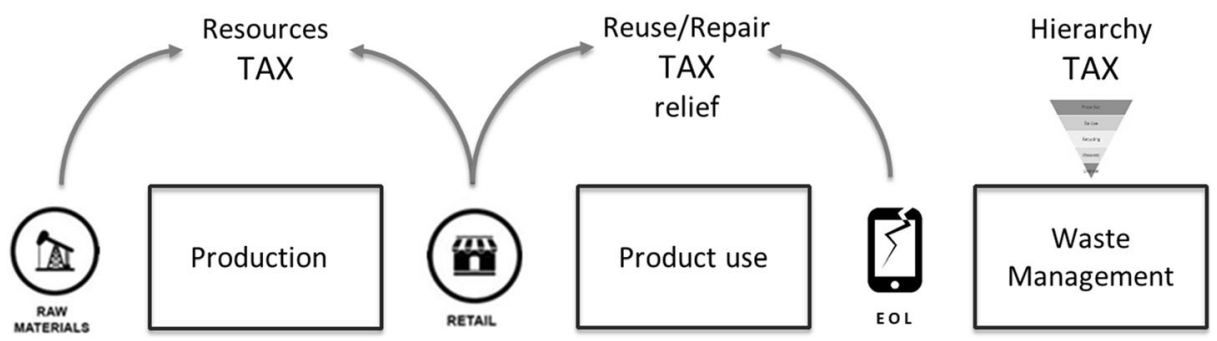

Fig. 1 Circular Economy Taxation Framework including (1) a natural raw material resource tax, (2) reuse/repair tax relief and (3) a waste hierarchy tax at the end of life of products 
available - provided that the level of the tax is high enough to at least balance the difference of prices between virgin raw materials and secondary materials (exempt of tax), which could lead to increased circularity in production systems. However, Söderholm [17] concluded that virgin material taxes may lead only to limited use of secondary raw materials since the own-price elasticity of supply for these alternative materials typically is very low.

In terms of macroeconomic fiscal policy, the demand for raw materials is typically indirect, i.e. the demand occurs due to the volume of consumer goods produced by the given materials. Therefore, raw material resources form the basis of economic activity and are likely to continue to do so in the future. Thus, the long-run price elasticity of demand may be considered low, and raw material resources could thus represent a stable tax base for governments $[15,17]$.

\section{Use Stage of the Life Cycle}

In the product use stage, a reuse/repair value added tax (VAT) relief is proposed. This is a generally accepted tax intervention which aims at increasing the affordability and availability of repair services and at boosting the uptake of reuse as a significant option in consumers' decisions concerning their old products. Therefore, a reduced VAT rate on repairs could increase the ability of local shops to offer repair and maintenance services, which are in line with the goal of increasing resource efficiency in the economy as whole.

The EU CE action plan (COM(2015) 614 final) states that "price is a key factor affecting purchasing decisions, both in the value chain and for final consumers. Member States are therefore encouraged to provide incentives and use economic instruments, such as taxation, to ensure that product prices better reflect environmental costs. [...] Once a product has been purchased, its lifetime can be extended through reuse and repair [...]. The reuse and repairs sectors are labour-intensive and therefore contribute to the EU's jobs and social agenda". It is also important to mention that in the EU, small- and medium-sized enterprises (SMEs) represent more than $95 \%$ of all firms and provide more than $67 \%$ of total employment [23]. SMEs can play an important role in a CE transition by providing sustainable, yet labourintensive services such as repair and refurbishing [24].

Reduced VAT rates for repair and reuse can also address externalities. By prolonging the life of products, significant savings in material and energy use can be achieved [25] and partially offset new production of consumer goods [26]. Moreover, reduced VAT rates are not expected to have negative implications for the functioning of the internal market as the relevant products and services are typically not traded across EU borders [27].

Despite the perceived benefits of reduced VAT rates for repair and reuse, there is a lack of real-life examples of implementation. One exception is the government of Sweden, which in January 2017 introduced a tax reduction on repair of certain products. The VAT rate on repair was reduced from 25 to $12 \%$ for products such as textiles, shoes, leather products and bicycles. The aim of the reduction was to encourage reuse and repairs [28]. Another instance of tax reduction in Sweden includes a deduction of 50\% (RUT tax deduction) on the labour costs for home repairs and maintenance and was first implemented in 2007 and updated in 2016 [29]. The updated version was implemented in 2017 together with the VAT reduction for repairs (Revision 2016:1055 of the income tax law 1999:1229).

Although the design and implementation of this taxation incentive has not been studied extensively, it consists an integral part of the proposed Circular Economy Taxation Framework that can succinctly address the issue of repair and reuse of products at the use stage of the life 
cycle. Aided by the Swedish example of implementation, the anticipated results and effectiveness of this policy intervention are discussed in the "Results and Discussion" section.

\section{End of Life Stage of the Life Cycle}

In the EOL stage, a "waste hierarchy tax" is proposed, i.e. a progressive tax which follows the "waste hierarchy" principle, with the tax rate decreasing progressively from landfilling (highest) to recycling (lowest), and is set to zero for any level above recycling.

Palmer and Walls [16] suggest that a tax on virgin raw materials can only correct the external costs resulting from extraction processes, but not external costs resulting from waste disposal. Additionally, no single tax can generate an optimum level of both downstream and upstream impacts, so multiple policy instruments would be necessary to fully internalise these externalities [30]. Therefore, it is considered imperative to complement the raw material resource tax and repair/reuse VAT relief with a waste tax that accounts for externalities at the EOL of products.

A common approach that has been extensively used in EU Member States (MS) is the socalled landfill tax. A review of the waste management performance of all MS over the period 2001-2010 [31] has concluded that landfill taxes played a major role in improving the waste management practices in MS and enabled them to divert considerable amounts of waste away from landfills to other more environmentally sound waste management options, according to the principles of the "waste hierarchy". The waste hierarchy constitutes the central principle of EU waste management, as it is expressed in Article 4 of the Waste Framework Directive (2008/98/EC). The waste hierarchy addresses the prioritisation of waste management options according to environmental and resource efficiency aspects. It includes the following waste management operations: (a) waste prevention; (b) reuse and preparation for reuse; (c) material and biological recycling; (d) energy recovery from waste; and (e) disposal to controlled or uncontrolled landfills, land or water.

Following the reasoning of implementing landfill taxes in EU MS and the observed results of the tax in diverting waste towards higher stages of the waste hierarchy, notably energy recovery and material recycling [31], a waste hierarchy approach is proposed to complement the Circular Economy Taxation Framework. According to the logical reasoning, since a tax on landfill made it uneconomical to dispose waste in landfills, a similar (but proportionately lower) tax on waste to energy (WTE) incineration would divert waste from incineration to recycling. Finally, a tax on recycling of waste would make the "preparation for reuse" and reuse of EOL products the most economically desirable option. However, under the condition that the tax is high enough to offset costs from other waste treatment options. That is to say, that after the implementation of the tax, landfilling becomes too costly compared to incineration, and respectively incineration is too costly compared to recycling. There are only a few examples of incineration taxes imposed on top of landfill taxes in MS, but the effectiveness of these to divert waste towards recycling has been inconclusive. For instance in Sweden, the incineration tax was evaluated as inefficient and counterproductive since it did not lead to the anticipated waste diversion and lead to increased waste fees and energy prices for the municipalities [32]. Taking this into account, it is important to set the tax rate quite high so as to overcome price levelling by energy sale revenues.

Moreover, environmental and social conditions must be taken into account when designing the tax architecture within a sustainability context. Although the tax level would be signalling the preferential waste management option according to the waste hierarchy, it might be 
necessary in certain occasions to depart from the hierarchy in accordance to the provisions of the Waste Framework Directive (2008/98/EC). In Article 4 of the Directive, it is stated that the preferred waste management option is the one that delivers the best overall environmental outcome, taking into account general environmental protection principles, technical feasibility and economic viability, the protection of resources as well as the overall human health, economic and social impacts. For instance, in some cases, incineration might be more economically viable than landfilling after introducing the suggested tax measures, but simultaneously it might be comparatively environmentally inefficient or even more polluting than landfilling, depending on the nature of the material, and it may result into serious environmental and social side effects (e.g. health concerns in urban areas).

Finally, it is worth noting that although the waste hierarchy is addressing waste management, step (a) waste prevention and partially step (b) reuse and preparation for reuse of the hierarchy deal mainly with non-waste. Waste that is prevented is waste not generated, and reuse of a product means that the product did not become waste in the first place [33]. Therefore, within the "waste hierarchy tax", any treatment option higher than recycling is not subject to a taxation rate.

Concluding the "Circular Economy Taxation Framework" section, environmental taxes in general are considered to be "growth-friendly", as they are less distortive compared to taxes on labour and income, while the administration and transaction costs of such taxes are lower than that of other taxes (notably income taxes) [15]. Furthermore, the efficiency losses from environmental taxes are far less compared to labour taxes [15].

\section{Methodology}

The research in this contribution was based on a mixed methods approach, using a variety of secondary sources, to analyse the specificities of each proposed taxation measure. Literature relevant to environmental fiscal interventions, and more precisely on material resource and waste fiscal policies, paved the way for the conceptual development of the Circular Economy Taxation Framework which is presented in the "Circular Economy Taxation Framework" section. For the in-depth analysis of the different proposed taxation measures within the lifecycle stages of the framework, a variety of research methods was necessary. More mature concepts, such as material resource taxes, were analysed based on reviewing the existing literature on the subject. The analysis of tax relief on repairs was based on the work of Almén et al. [29], who conducted interviews with relevant stakeholders in Sweden, where this economic policy instrument has been implemented since 2017. Finally, for the waste hierarchy tax - a novel proposition in the taxation framework - the analysis was based on macroeconomic modelling (computable general equilibrium model (CGE)) conducted by Lokrantz [34] to analyse potential impacts of future implementation by comparing different scenarios. More details on the methods are presented in the following paragraphs.

The literature review, interviews and macroeconomic modelling were focused on Sweden as a case study. The reason for focusing on Sweden is due to the fact that most of the proposed taxation interventions have already been implemented in Sweden to a higher or lesser degree. Natural resource taxes are implemented in Sweden, for instance in the case of natural gravel [35]. A VAT discount in repairs of products such as textiles, shoes, leather products and bicycles has been implemented in Sweden since 2017 [4], and a tax return is calculated for repairs of white goods and IT equipment at home [29]. Sweden is imposing a tax on landfilling 
(500 SEK per tonne of waste) and incineration (100 SEK per tonne of waste) [36]. Thus, most of the elements included in the Circular Economy Taxation Framework proposed in this contribution have been implemented in the context of Sweden, and therefore it constitutes a relevant case study to analyse in more detail. However, the Circular Economy Taxation Framework includes additional elements which have never been encountered in literature, and this is the reason for employing macroeconomic modelling and scenarios development, in the case of the waste hierarchy tax.

Starting with the natural raw material tax relevant literature was sought for, using the basic keywords "material tax", "natural resource tax" and variations of these forms. The search was strictly limited to a narrow range of "material" taxation, because using broader terms such as "environmental tax" or "green tax" would return a large amount of literature relevant to pollution taxes. Further, natural resources such as land, water and air were excluded manually from the search results, and a strict focus was maintained around materials (e.g. metals, minerals, plastics, wood). The literature review commenced with searching for scientific publications using databases such as Web of Science, Scopus and Google Scholar. Then snowballing technique was used (in terms of keywords, authors' names and journal titles) to expand the preliminary reference list. In addition to peer-reviewed literature, "grey" literature sources were also examined, since taxation regimes are discussed also by practitioners outside of academia. Relevant government consultation documents and consultancy reports were also included in the search results.

Almén et al. [29] developed a qualitative methodology to analyse the effects of a tax relief on repairs in Sweden by conducting semi-structured interviews with companies that perform repairs. This method was chosen for receiving a direct account of the interviewees' own experiences and expectations regarding the repair tax deductions. The interview study followed an inductive approach with the aim to investigate and draw conclusions through the analysis of the collected data and without adopting prior theoretical hypotheses [37]. The targeted interviewees were chosen among the sectors included in the regulation (shoes, bicycles, white goods, IT equipment) and depending on whether they perform repairs or not. In total, 22 Swedish SMEs in the repair sector were interviewed. The interviewed companies included five shoe repair companies, five bicycle repair companies, five white goods repair companies and seven IT repair companies. The analysis of the interviews was qualitative based on the collected data without using any particular software for the coding of emerging themes; thus, a risk of subjectivity and analysis bias is present in the results.

For analysing the effects of a waste hierarchy tax in the Swedish economy and its resource efficiency potential, Lokrantz [34] developed a simplified computable general equilibrium (CGE) model of the Swedish economy, which was extended with equations representing waste flows and environmental preferences. The simplified model included a few basic assumptions. Firstly, the model considers a closed economy, meaning that neither international trade nor foreign influences are modelled. Secondly, the model considered a static economy in the sense that it does not include any dynamic elements like savings or investment which depends on intertemporal decisions over time. Lastly, the model assumed that there are no market imperfections, there is perfect competition and no uncertainty. The series of assumptions were considered necessary to develop a robust model that would give meaningful results without overcomplicating the economy structure.

The benchmark data for the model calibration consisted of data on quantities of treated waste and Swedish national accounts retrieved from Eurostat [38, 39]. The base year was set to 2016, which is the latest year with available data on quantities of treated waste. The waste data 
were organised after treatment technology and after the European Waste Catalogue's classifications of waste categories.

To discuss the different possible ways of implementation and impacts of a waste hierarchy tax in Sweden, Lokrantz [34] developed alternative policy scenarios and compared them to the baseline - the current situation in Sweden. The policy scenarios included (A) waste hierarchy tax, (B) waste hierarchy tax with a recycling subsidy and (C) waste hierarchy tax with a technology shift. The scenarios are briefly summarised below and in Table 1.

\section{Scenario A: Waste Hierarchy Tax}

This scenario was based on the waste hierarchy principle, aiming to divert waste towards recycling and eventually reuse and prevention. In this setting, the taxation framework differentiated between the different treatment technologies and ranked waste disposal, incineration and recycling according to the waste hierarchy. Hence, all levels were taxed with different tax rates, given their position in the waste hierarchy (see Table 1). Accordingly, the tax rate for waste disposal was set at 500 SEK per tonne, which is the same as the Swedish landfill tax [36]. The incineration tax and the recycling tax were set gradually lower, at 300 SEK and 100 SEK per tonne, respectively. Thereby, recycling would become more financially attractive, while harmful treatment alternatives like landfill and incineration were penalised.

\section{Scenario B: Waste Hierarchy Tax with Recycling Subsidies}

The tax on recycling was replaced with a subsidy, resulting in a policy intervention that introduces two different policy instruments. Combining taxes on waste with a subsidy is encountered by Schwerhoff and Franks [40] who combined environmental taxes with subsidies on capital and output, and based on literature about resource taxes and recycling subsidies $[16,41]$. The tax rates for the different treatment technologies were the same as in the previous scenario (see Table 1), but instead of taxing recycling, in this scenario the government subsidised it. The subsidy was modelled as a negative tax [40]. With the recycling subsidy, firms were given a strong incentive to shift from waste disposal and incineration to recycling.

\section{Scenario C: Waste Hierarchy Tax with a Technology Shift}

The effect of the waste hierarchy tax was analysed in the presence of a technological improvement in the production sector. According to Böhringer and Rutherford [42], technological change plays an important role when assessing policies for circular economy and resource efficiency. This is because technological shifts can lead to more resource efficient production but can also result in a rebound effect [42]. Following this line of thought, in

Table 1 Summary of scenario settings (level of tax/subsidy expressed in Swedish currency (SEK) per unit), adapted from [34]

\begin{tabular}{lllll}
\hline & Baseline & Scenario A & Scenario B & Scenario C \\
\hline Disposal & 0 & 500 & 500 & 500 \\
Incineration & 0 & 300 & 300 & 300 \\
Recycling & 0 & 100 & 0 & 100 \\
Subsidy & 0 & 0 & 100 & 0 \\
\hline
\end{tabular}


response to the waste hierarchy tax reform, it was assumed that firms are willing to invest in new, more efficient technology which is captured by a shift in productivity, modelled as $10 \%$ increase in the productivity coefficient.

\section{Results and Discussion}

The results of the literature review and the secondary source material are presented and discussed separately for each tax intervention in the following subsections, followed by a separate subsection discussing the potential and challenges of the Circular Economy Taxation Framework as a whole.

\section{Natural Raw Material Resource Tax}

For a natural raw material tax to create a positive response from industrial actors or consumers, leading to more resource-efficient practices, the tax level needs to be sufficiently high regardless of where in the value chain it is applied [9, 20]. Baptist and Hepburn [43] recognise that the implementation of such a high tax rate could be extremely difficult in the real economy. The material tax in itself could be expected to have a moderate effect because own-price elasticity of demand is often low for materials [17]. This suggests that it is important to understand how a wider set of policies, in addition to the tax, interact with raw material markets [41]. Thus, the development of material taxes requires careful consideration before design and implementation. Moreover, issues related to imports and exports of raw materials may create competitiveness asymmetries and require particular attention [44].

The effects of a tax on natural raw material resources may differ according to the phase of the value chain in which it is applied. Demand-price elasticity as well as market dynamics and innovation potential can vary at different stages of the value chain of a material [20]. For a single non-renewable material resource, there are three stages in the value chain in which a tax could be applied: (a) at the extraction of the raw material, (b) as input of the material at the first industrial use and (c) at the final consumption of products (embedded material content).

A raw material tax imposed at the extraction stage in a region would directly affect the international trade of the targeted commodity. The tax would bring domestic producers at a cost disadvantage compared to foreign producers, leading inevitably to the reduction of domestic extraction, to a corresponding increase in imports and potentially-depending on demand elasticity - to price increase [41]. The increase in imports of a raw material would imply increase of production in third countries. Consequently, the tax would not have a direct effect on the extraction of the targeted material elsewhere, since the level of use in the domestic market would remain unchanged through tax-exempt imports, but the net environmental effect could possibly be negative if the extraction technologies abroad are worse than the domestic ones [20].

Therefore, it is important to introduce appropriate counterbalance measures to mitigate adverse environmental impacts of such shift in extraction location, for instance through the implementation of a border tax adjustment mechanism on imported resources [20]. In addition to neutralising the effects of the tax on domestic producers, it would also protect the competitiveness of domestic industries. However, the effect on the competitiveness of the domestic industry would be much smaller if the tax is not calculated on the basis of the quantity of materials extracted or imported, but on the estimated quantity of raw materials that 
are extracted globally to produce products that are used in Sweden [44]. Other measures that could potentially prevent competitiveness losses for domestic industries could be to levy the tax on materials and products used domestically in Sweden, including imported products as well as domestically produced products, but to exempt materials produced in Sweden for export [44].

Another option for implementing a material tax is that of a "material input" tax, which means tax levied at the resource input of manufacturing (the first time a material is used). It differs from a resource tax at the extraction stage, as a supplementary border adjustment tax is not needed because this type of tax does not distinguish between domestic and imported materials. In order for such a tax to be reasonably implemented, the main requirement would be that there is a limited number of product groups subject to this tax; otherwise its implementation would be challenging [20]. A material input tax could, instead of encouraging substitution of the taxed material, stimulate technological innovation aimed at reducing the use of that material, for instance be "light-weighting" which would be favourable in terms of resource efficiency [45].

The last possible stage for introducing a raw material tax is at the final use of products. Tax on the consumption of products that include large amounts of a specific resource is possible; however, its application might prove rather challenging and its effectiveness uncertain. There could be significant problems in identifying the share of a specific material within a final product, making the taxation base uncertain [20]. Taxation at this stage might be better thought of as a tax based on the intensity of multiple materials, possibly taking a life-cycle analysis (LCA) perspective. Andersen [46] argues that once reasonable estimates are available for the external costs of a product, it would be possible to internalise these in market transactions by introducing relevant environmental taxes and charges. This allows for a first theoretical approach on the application of a PEF-based (Product Environmental Footprint-based) taxation structure. The latter would be interesting to investigate further; however, the sheer amount and diversity of products and product groups would be a formidable challenge, to say the least.

Increasing material recycling is a basic principle of resource efficiency [3]. Taxation schemes based on material input or consumption taxes would ideally target only virgin materials, and not their recycled equivalents. This could pose challenges in designing taxes for certain materials (e.g. metals, paper) as their recycling rates are already quite high [20]. Furthermore, due to global recycling markets, recycled metals such as iron could be easily integrated into intermediate products and parts, and their detection in final products would be difficult. Ekvall et al. [9], on the other hand, suggest that the tax should be applied also on recycled materials, since the overall aim of such a tax would be to increase material efficiency, and therefore the reduction of material input regardless if the material is virgin or recycled. Moreover, a material tax should be levied on all types of materials in order to avoid burden shifting between materials. It could be levied even on renewable materials, as renewable resources need also to be used efficiently, because their production rate is limited [9].

The possibility of substitution constitutes a critical factor for the effectiveness of resource input and consumption taxes and forms a major drawback if designed to address a single material resource. Taxing a single material might result in substitution rather than overall resource efficiency [45]. Moreover, substitutes of the taxed material may have other unpredictable environmental disadvantages, such as higher energy intensity or lower recyclability [20]. Taxing material groups could be a better approach, but that might shift the problem to comparing the material groups themselves, for instance plastics versus metals, instead of single material groups, such as copper versus aluminium (i.e. metals). 
A tax on material resource input on new production could contribute also in establishing a competitive advantage of second hand goods (reuse), since competing manufactured goods would have increased raw material costs and thus become more expensive [47].

Concluding, even under a trade-neutral taxation scheme, based on a material resource tax and supplemented by border adjustment countermeasures, there is still a risk of cross-material substitution effects with uncertain resource and environmental implications. However, a global multilateral extraction tax on all non-renewable and non-energy resources could be considered a viable solution, since its expected effect would lead to a global price increase of resources resulting in global demand reductions [20]. The actual design and implementation of such a resource tax, however, would be a major challenge in the current global political environment.

\section{Value Added Tax Reduction in Product Repair and Reuse}

The analysis of the "repair/reuse tax relief" component of the proposed CE taxation framework is based on the empirical study by Almén et al. [29], which aimed at assessing whether there has been a change in repair activity since the implementation of the VAT reduction and RUT tax deduction in Sweden. The focus of the study was exclusively on four economic sectors, which are specifically targeted by the tax reduction legislation (i.e. shoes, bicycles, white goods and IT goods).

Out of the twenty two interviewed companies across the four different sectors, only nine noticed an increase in the number of repairs executed since the implementation of the tax changes in 2017. Of those nine companies, two were shoe repair companies, three were bicycle repair companies, zero in white goods repairs, and four were companies that performed IT goods repairs (e.g. repairing mobile phones, computers, televisions). However, the majority of the companies could not determine if the increase was caused by the tax deductions or not. In other words, a large portion of the interviewed companies were not considerably affected by the lower tax regime for repairs. A summary of findings is presented in Table 2.

The results showed that a relative majority of companies in the bicycle and IT sector could claim an increase in the number of repairs. On the other hand, most of the companies in the other two sectors, white goods and shoes, did not observe any significant changes. There are several reasons that might explain these differences between the sectors. For instance, the reason why no changes were noticed in the white goods sector might be related to the fact that "it does not depend on whether the taxes are low or not, but rather the high purchasing price of new products", as one interviewee highlighted. The product category of white goods can be in general more expensive than shoes, bicycles and IT goods (although some high-end IT products can be equally expensive). The difference in price between repairing existing products and buying a new product is larger, which increases the willingness to repair. Thus, the number of repairs did not increase entirely due to the effect of the reduced tax, since the majority of consumers would prefer to repair than buying new in any case.

Regarding the shoe repair sector, the reason no changes were noticed may be due to a different market situation and the view of shoes as more easily replaceable, compared to other sectors. For people to actually repair their shoes, these must be of high quality and possibly expensive for making it worth the effort to repair them. The shoe market can be both expensive and cheap depending on brand and shop, just like the other sectors. However, low-quality and dispensable shoes (according to fashion trends) are usually not worth repairing compared to expensive and "classical" high-quality shoes. One interviewee particularly stressed that the main problem can be spotted in the growing "throwaway culture". This linear behaviour seems 
Table 2 Summary of the interview results with 22 Swedish SMEs in four sectors (shoes, bicycles, white goods, IT equipment) that are eligible for repair tax reduction according to Swedish legislation

\begin{tabular}{|c|c|c|c|}
\hline $\begin{array}{l}\text { Economic sector } \\
\text { No. of companies }\end{array}$ & $\begin{array}{l}\text { Perceived tax } \\
\text { effectiveness No. } \\
\text { of companies (share) }\end{array}$ & $\begin{array}{l}\text { Tax did not } \\
\text { influence repairs No. } \\
\text { of companies (share) }\end{array}$ & $\begin{array}{l}\text { Possible reasons for no } \\
\text { tax effect }\end{array}$ \\
\hline Shoes -5 & $2(40 \%)$ & $3(60 \%)$ & $\begin{array}{l}\text { - Shoes viewed as dispensable } \\
\text { - Fashion/trends } \\
\text { - Variable (low) quality of product }\end{array}$ \\
\hline Bicycles -5 & $3(60 \%)$ & $2(40 \%)$ & - Variable (low) quality of product \\
\hline White goods - 5 & $0(0 \%)$ & $5(100 \%)$ & $\begin{array}{l}\text { - High cost of new product makes } \\
\text { repairs preferable }\end{array}$ \\
\hline IT equipment -7 & $4(57 \%)$ & $3(43 \%)$ & - Lack of information about the tax \\
\hline Total -22 & $9(41 \%)$ & $13(59 \%)$ & $\begin{array}{l}\text { - Lack of information about the tax } \\
\text { - Price difference of repair vs. buying } \\
\text { new product } \\
\text { - Variable (low) quality of product } \\
\text { - Product design/ difficulty to repair }\end{array}$ \\
\hline
\end{tabular}

The table shows the percentage of companies that experienced increase in repair services as a consequence of the tax, and the main reasons why the rest of the companies did not experience any effect of the tax

to be embedded in the purchasing decisions of Swedish consumers, and in this regard, the implementation of the VAT reduction did not have a noticeable impact on the interviewees' businesses. This may imply that further policies and/or initiatives might be required to address such behavioural inconsistencies that cannot be tackled just by the implementation of a reduced tax rate for repairs.

In order to address the reasons behind the observed limited effectiveness of the tax reduction in increasing repairs, it is essential to identify the barriers for repair in the current situation. Barriers that were highlighted by the interviewees in all the above sectors included (a) lack of knowledge regarding the reduction of the tax for repairs, (b) the difference in prices between repairs and buying of new products, (c) perceived and actual product quality and (d) product design, which makes it difficult to repair products and to access spare parts.

Interviewees from all sectors, except the bicycle sector, mentioned that there is a lack of knowledge regarding the existence of a tax reduction among their customers and that it is unlikely that the majority of their repair operations can be attributed to the tax reduction. On the other hand, in the bicycle sector that the tax reduction was more prominent, after an initial spike on repairs by the time of the introduction of the tax reduction, repair activities have levelled off gradually and now bicycle repairers cannot see a difference compared to the level of repairs before the VAT reduction.

It is therefore of paramount importance to communicate the tax reduction intervention better with the public and to disseminate more information about the nature and the benefits of repairs. The information should be aimed at the people who are not aware that there is a possibility to repair products at a cheaper price compared to before the VAT reduction was implemented.

Another identified barrier was the relatively low purchasing price of new products compared to the cost of repair, which deterred customers from repairing their product instead of buying a new one. In addition, the quality of products plays a significant role in the decision whether a product is worth repairing. Two of the interviewees in the bicycle sector stressed that high-quality bicycles are worth repairing compared to low-quality bicycles, which are viewed as disposable and are not worth the effort (time and money) to repair. This applies on products in all sectors. If consumers turn to buying more high-quality products, the chance that they will 
see worth in repairing the product increases. Therefore, by widening the price gap between a new purchase and the repair of already acquired products would increase the willingness to repair by the customer.

Moreover, the quality of the repair work is critical for the wider uptake of repair activities. The price of a new product usually includes a guarantee that the product will function according to quality specifications for a certain amount of time; otherwise the customer has the right of refund or replacement [48]. In the case of repairs, this is not the standard practice and it could act as a deterrent for repairs even through the price would be lower compared to buying new. Therefore, another proposed solution mentioned by one of the bike repair companies was a certification among workshops. This could lead to an increase in the number of repairs since customers will know that the repair is of high quality. This is reiterated in literature, also in the case of IT goods [49], where a quality labelling scheme can potentially boost consumer confidence in repairs.

Finally, to facilitate easier and more cost efficient repair services, the products should be easier to disassemble and contain less diverse and hazardous materials. For instance, an interviewee in the shoe repair sector mentioned that "high quantities of plastic in the shoes make them harder to repair or not repairable at all". Therefore, the selection of materials and product design can have significant effect on the feasibility and the cost of repair, which in turn would negate the effect of a tax reduction no matter what the level of the tax and the potential gain would be. Related to product design and the feasibility of repairs, another aspect which needs to be considered is the availability of spare parts. If consumers choose to keep their old product for a long time, repairers may not have the spare parts needed due to the discontinuation of a certain product/model in the market. This is a barrier especially relevant for IT products where the development of new products is progressing rapidly. Therefore, availability of spare parts in the market and at reasonable (affordable) price is a prerequisite for a wellfunctioning repair sector [50], which can benefit from a tax reduction.

Concluding, the implementation of a tax reduction on repairs of certain products (i.e. shoes, bicycles, white goods, IT goods) in Sweden since 2017 did not have a significant impact according to the study by Almén et al. [29]. Some companies in the bicycle and IT goods sectors observed an increase in the number of repairs; however, the majority of the interviewees could not link the increase in repair frequency to the respective tax reduction. The implementation of the tax reduction for repairs did not have the desired effect so far. This may imply that further policies and/or initiatives are needed as the effect of the repair tax reduction alone is not expected to result in any significant changes in consumer behaviour.

\section{Waste Hierarchy Tax}

For the quantification of the effects of a waste hierarchy tax in the Swedish economy and its associated resource efficiency implications, Lokrantz [34] developed and applied a static, closed economy CGE model for Sweden. The quantitative nature of CGE models are appropriate tools for assessing such policies as they allow for quantifying the effects of the waste hierarchy tax on the relation between the waste and the macroeconomy. By evaluating the introduction of a tax based on the waste hierarchy principle under different scenarios - as presented in the method section of this article - the conditions in which the tax has a positive or negative impact on the Swedish economy can be analysed.

The main results of the CGE modelling are presented in Table 3, where the different scenario equilibrium solutions are shown as the percentage change from the baseline. This 
convention simplifies the presentation of the results and makes it easier to compare the scenarios' results.

The simulation results for Scenario A change significantly from the baseline. The results show that introducing a waste hierarchy tax can lead to a reduction of waste landfilled and incinerated by $14.81 \%$ and $2.98 \%$, respectively, compared to the baseline. Recycling increases by $26.14 \%$. This suggests that the waste hierarchy tax can be an effective tool for shifting waste output to higher levels in the hierarchy. The government's tax revenue appears to increase by $94.01 \%$ in relation to the baseline, while there is a moderate drop in the national GDP by $0.37 \%$. In relation to previous studies, the difference between the baseline situation and the waste hierarchy tax can be understood through the ability of the tax to affect incentives and behavioural structures $[51,52]$.

Tietenberg [53] has illustrated how a policy reform aimed at reducing pollution needs to account for firm heterogeneity. Accordingly, this means that the tax should include different tax rates for different firms to be effective. This proposition is also confirmed by King et al. [54] who showed that environmental taxes should be targeted at specific goods/sectors to have an impact. Consequently, the same line of argument holds for the waste hierarchy tax. The waste hierarchy tax gives a clear signal of what type of waste treatment is considered unwanted through the differentiated tax rate.

Moving to Scenario B, the waste hierarchy tax is combined with a subsidy on recycling. While the scenario is similar to the pure waste hierarchy tax, there are some key differences in the simulation result that should be highlighted. Beginning with the impact of the tax subsidy on waste, the change in waste disposal and incineration from the baseline is larger than before with 34.23 and $8.61 \%$ decline, respectively. The level of recycling on the other hand rises by approximately $42.55 \%$, which is considerably higher than in Scenario A. These results reflect those by Schwerhoff and Franks [40] who have demonstrated that subsidies can increase efficiency and pollution reduction in the sector that benefits from the subsidy. Therefore, the results suggest that a subsidy could be an effective method to shift waste towards recycling.

However, the results also highlight some downsides to the subsidy approach, resulting in a higher reduction of GDP with $0.89 \%$. This result is in line with Xie and Saltzman [55] who showed that even if a subsidy has a positive impact on pollution, the effect on production and GDP is negative due to limited capital resources. Altogether, this implies that the costs of the subsidy, including less tax revenues, government spending and lower GDP, must be accounted for.

In Scenario C, following the suggestions of Böhringer and Rutherford [42], the impact of the waste hierarchy tax under a shift to more efficient technology is assessed. A shortcoming of this scenario is the fact that the theoretical framework relies on the assumption of exogenous

Table 3 CGE modelling main results (figures represent the percentage change from the baseline), adapted from [34]

\begin{tabular}{lllll}
\hline Variable & Baseline & $\begin{array}{l}\text { Scenario A } \\
\text { (waste hierarchy) }\end{array}$ & $\begin{array}{l}\text { Scenario B } \\
\text { (recycling subsidy) }\end{array}$ & $\begin{array}{l}\text { Scenario C } \\
\text { (technology shift) }\end{array}$ \\
\hline GDP & 0.00 & -0.37 & -0.89 & 6.82 \\
Transfers/government tax revenue & 0.00 & 94.01 & 38.12 & 113.41 \\
Waste for disposal & 0.00 & -14.81 & -34.23 & -7.63 \\
Waste for incineration & 0.00 & -2.98 & -8.61 & 10.06 \\
Waste for recycling & 0.00 & 26.14 & 42.55 & 40.73 \\
\hline
\end{tabular}


technology. According to Böhringer and Rutherford [42], modelling technology as exogenous is a disadvantage when analysing technological change in relation to resource efficiency and waste. This is because the technology shift is not captured as an outcome of, for example, investment or research and development, which are important features for increasing resource efficiency [42]. Despite this, introducing a technological change scenario in the modelling of the waste hierarchy tax can still provide valuable insight to the analysis. With the combination of the waste hierarchy tax and the technology shift, the impact of the tax is noticeably different compared to the previous scenarios. The reduction of waste disposal at $7.63 \%$ from the baseline is smaller than in Scenario A and Scenario B. Moreover, in contrast to the previous results, both incineration and recycling levels rise with 10.06 and $40.73 \%$, respectively.

Consequently, the technological improvement offsets the positive impact of the tax framework which is in line with the findings by Böhringer and Rutherford [42]. Following their reasoning, the results exemplify the so-called rebound effect that follows a technology shift. If the shift leads to lower production costs and prices, these changes can in turn lead to increases in demand and supply, which offsets the potential gains from technological change in resource efficiency and waste minimisation [56].

In summary, the results indicate that the waste hierarchy tax which accounts for the three bottom steps in the waste hierarchy has an impact on waste and would most likely induce further waste management improvements in Sweden. However, the results also highlight the fact that the impact of the tax is sensitive to its design and to the reactions in other sectors of the economy.

Based on the results of the CGE modelling of the waste hierarchy tax and insights from previous studies, a main macroeconomic concern is related to the question of the distributional effects on resources and capital that could follow the introduction of the tax: who wins and who loses due to the policy change? This question is important to consider for at least two reasons. Firstly, if the cost of the redistribution exceeds the gains, policymakers might have to abolish the policy to avoid economic and political damages [57]. Secondly, the group that loses because of the policy might stop its implementation if they have the power to do so [54]. In relation to the waste hierarchy tax, the losers would for example be those actors whose waste cannot be easily shifted towards higher steps in the hierarchy with lower tax rates. This implies that the tax might need to be combined with other policies to mitigate the potential negative distributional effects.

Lastly, the CGE modelling developed by Lokrantz [34] was subject to several limitations. To capture the effects of the waste hierarchy tax, several simplifications and assumptions were made, resulting to a "simpler" design of the model. Therefore, there is a potential for several possible future extensions. Future work could modify the model to include an international sector, with imports and exports of material resources. Additionally, it would be interesting to explore how to extend the model to capture other relevant features of the circular economy, for instance reuse of waste or extended product lifetimes.

\section{Towards a Framework for Circular Economy Taxation}

From the analysis of the different taxation interventions in the previous sections - targeting specific life-cycle stages of materials - it becomes apparent that the implementation of each one individually entails considerable challenges. Therefore, it is reasonable to bundle these interventions in a wider fiscal policy framework that counterbalances the observed weaknesses and creates stronger pull effects on purchasing decisions, enables behavioural change and 
facilitates a potential shift of the economy as a whole. The proposed Circular Economy Taxation Framework (Fig. 1) attempts to reconcile the diverse objectives of the different proposed taxes towards a common overarching aim, that of a circular economy transition.

The main outcomes of the potential implementation of a natural raw material tax indicate that (a) the level of the tax needs to be sufficiently high to have an impactful effect and (b) that the application needs to be horizontal to avoid materials substitution and to increase overall resource efficiency. Moreover, the implementation of the tax would result in competition risks across industrial sectors and national economies. The introduction of resource use taxes would contribute in establishing a competitive advantage of second hand goods (reuse) or services that substitute resource inputs, e.g. in the case of product-service systems [47]. Additionally, from a dynamic efficiency perspective, the tax could make R\&D investments in such resource efficient business models (also known as circular business models) more competitive and in this way could influence innovation trajectories towards more resource-efficient patterns of production and consumption [10].

In the "Value Added Tax Reduction in Product Repair and Reuse" section, a critical barrier identified had to do with the difference in price between repairing existing products and buying a new product. When the price of new products increases, consumer preference towards repairing existing products - instead of buying new - also increases. Therefore, the introduction of a high material input tax coupled with a "generous" tax relief for repairs would incentivise consumers to choose repairs and prolonging the life of products. Moreover, the analysis of the effect of a waste hierarchy tax showed that waste generally would be redirected towards higher waste management options in the hierarchy, resulting in more recycling and potentially higher repair and reuse of EOL products. Although the effects of reuse were not captured by the CGE modelling by Lokrantz [34], it is a logical conclusion that waste holders would seek to avoid waste management fees and taxes by avoiding landfilling, incineration and recycling, and choosing to repair and reuse their existing equipment - to the extent possible (when ruling out the possibility of illegal disposal). If it is not possible to reuse the entirety of the EOL equipment, there is still a potential to salvage components and spare parts, thus reducing the level of material wastage [33]. In turn, salvaged parts could feed in repair activities, making them even more affordable to consumers by further sinking the cost of repairs. Salvaged components from EOL equipment could be sourced in lower prices than new spare parts (although this depends case by case). Moreover, in the case that spare parts are discontinued by the original manufacturer, the salvaged parts constitute a valuable source that enable the repair of a broken equipment that would have to be wasted otherwise.

Looking at all the elements of the proposed framework together, it is possible to discern a "sandwich" effect which pushes for more intense use of products over their lifetime and could more generally lead to product life extension, a prominent circular economy strategy [58]. The high price of using virgin raw materials from one side, and the high price of wasting raw materials on the other side, would ultimately lead consumers towards choosing more and more repair and reuse options which come with lowered costs (tax relief).

The Circular Economy Taxation Framework presented in this contribution can stand alone as an economic policy intervention, and it constitutes a holistic approach including all lifecycle stages of production and consumption, in a way that each of its constituent elements could not have addressed individually. However, its effectiveness towards achieving a wider multi-level and multi-stakeholder objective, such as the transition to a circular economy, would be limited if not complemented by an array of other policy instruments [59]. For instance, the taxation framework includes premises that affect market failures (externalities) and 
behavioural aspects (economic preferences) but fails to address sufficiently governance and institutional aspects. In the case of the natural raw material tax, issues concerning competitiveness between industries and national economies came up which could undermine the effectives of the tax if no counterbalance measures are taken. In the case of the repair tax relief, the empirical evidence showed a lack of public information that hampered its effectiveness. Moreover, the current production practices undermined the effectiveness of the tax since the difficulty of repairs and unavailability of spare parts were contributing factors to increased costs of repairs despite the tax relief.

The Circular Economy Taxation Framework could also be a useful add-on to existing CE policy frameworks, for steering consumer and firms preferences and internalising external costs. For instance, Milios [19] developed a comprehensive policy framework for material resource efficiency in the EU, which was lacking major fiscal components (Fig. 2). The Circular Economy Taxation Framework complements the Milios [19] framework, by adding the necessary economic elements in the policy mix, while the Circular Economy Taxation Framework benefits from the proposed policy instruments in several ways. The Ecodesign Directive (2009/125/EC) can regulate the durability, disassembly and recyclability of products as well as the availability of spare parts. By making products more easily repairable, the cost of repair would fall respectively and adding the tax relief on repairs, it would make it a more attractive and economical option. Moreover, a quality label for reused equipment would boost the confidence of consumers to trust the repair and remanufacturing processes, and coupled with the tax relief on repairs, it would increase their willingness to purchase reused goods. Finally, the proposed target for reuse (Fig. 2) could be facilitated by the waste hierarchy tax which does not assign any additional cost to the "reuse" option rendering it the de facto preferential option (not considering other associated costs of sourcing, repairs and distribution).

Finally, an efficient policy mix needs to consider the socioeconomic context of its implementation, including the potentially affected actors and interest groups, for instance firms that might lose market shares or investments as well as consumers [60]. This implies the need for certain approaches in the policy mix, which can redistribute revenues from the raised taxes back into the affected industries to provide support for implementing resource-efficient changes and innovation or develop skills training to create new job opportunities [10].

\section{Conclusions and Future Research}

The proposed CE fiscal policy framework constitutes an early attempt to reconcile economic considerations in the life cycle of products as a reasonable policy proposal that complements the overarching resource efficiency policy mix, as presented for instance in the EU strategy [61]. The framework includes a natural raw material tax, a repair/reuse tax relief and a waste hierarchy tax, which overall contextualises the first research question of this contribution.

To address the second research question, each of the constituent elements of the framework was individually scrutinised for their potential effectiveness and challenges of implementation, followed by an integrated discussion of the framework as a whole and in relation to other (noneconomic) policy instruments.

At the material extraction stage, a tax imposed in a region would directly affect international trade of the targeted commodity. Therefore, counterbalance measures would be required to neutralise the negative environmental effects of potential shift in production location that a 


\section{Product life cycle}

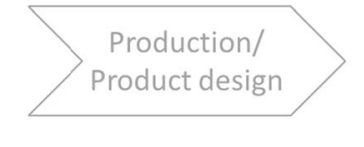

Eco-design incorporating material resource efficiency

- Design for durability

- Design for reparability

- Design for recyclability

- Availability of spare parts
Product/material standards
- Standards for resource efficient design
- Standards for secondary raw materials

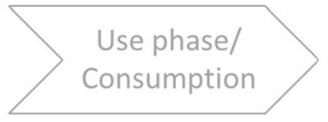

Green Public Procurement

- Criteria for product life extension

- Criteria for \% recycled content

- Criteria for chemicals and hazardous substances

- Criteria for EOL management

$$
\begin{aligned}
& \text { Quality labelling for } \\
& \text { Re-used products } \\
& \text { - Product labelling } \\
& \text { - Process labelling } \\
& \text { - Organisation labelling }
\end{aligned}
$$

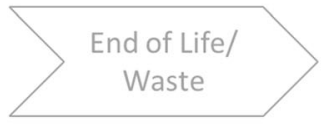

Binding Re-use target

- \% of EOL products

- \% of re-use market

Investment in recycling

- Capacity

- Technology

- Innovation

- Collection/sorting systems

Ban on the incineration of recyclable materials

\section{Coordination of product value chains \\ - On-line registers $•$ Match-making platforms • Public-private initiatives to engage stakeholders}

Fig. 2 Material resource efficiency policy framework with a life cycle perspective, developed by Milios [19]

resource tax would possibly lead to. The possibility of material substitution constitutes a critical factor for the effectiveness of resource input and consumption taxes and forms a major drawback if designed to address a single material resource. Taxing a single material might result in substitution rather than overall resource efficiency. Further, the potential substitutes of the taxed material may have other unpredictable environmental disadvantages, such as higher energy intensity or lower recyclability.

In the case of the Swedish VAT reduction in repair services, implemented since 2017, the results showed that it has not made a significant impact. However, some of the interviewed companies have observed an increase in the number of repairs. Despite this, the majority of the interviewees could not link the increase in repair frequency to the respective tax change. This implies that complementary policies and/or initiatives are needed. Suggestions to increase the number of repairs include better communication to the public in order to increase the awareness of the tax.

The CGE modelling results of the waste hierarchy tax showed a generally positive impact on waste generation and recycling, with minor negative effects on GDP growth and productivity. From the different scenarios analysed, the application of the waste hierarchy tax coupled with government subsidies to the recycling sector showed the highest potential for implementation.

Taking into account the specificities of each of the analysed economic interventions, it becomes apparent that the full potential of the individual instruments can only be realised when combined within a comprehensive policy framework including other economic, administrative and informative policy instruments. The fast evolving literature on the governance aspects of $\mathrm{CE}$ and the enabling policy approaches would benefit from the findings of this research by integrating some of the proposals and generating further research avenues or road mapping exercises for transition.

Further research is required both at the individual instrument and at the framework level. Each of the tax proposals needs a more detailed examination for its specificities of implementation, following the results of this study. Also, further research is needed for integrating the 
individual instruments in a consistent and comprehensive way to strengthen its overall impact on the policy mix. The integrative approach could make use of quantitative economic modelling to produce actionable results. However, the sheer complexity of the economic interactions within the proposed framework and across economic sectors might prove particularly challenging. Application within a national economy, as in the case of Sweden, might be a first step. Application of the framework to a wider context, e.g. the EU, could be of high significance under the new CE strategy and the "Green Deal" for Europe.

\section{Code Availability N/A}

Funding Open Access funding provided by Lund University. This research was supported by the Mistra REES (Resource Efficient and Effective Solutions) programme and funded by Mistra (The Swedish Foundation for Strategic Environmental Research).

\section{Data AvailabilityN/A}

\section{Compliance with Ethical Standards}

Conflict of Interest The author declares that he has no conflict of interest.

Open Access This article is licensed under a Creative Commons Attribution 4.0 International License, which permits use, sharing, adaptation, distribution and reproduction in any medium or format, as long as you give appropriate credit to the original author(s) and the source, provide a link to the Creative Commons licence, and indicate if changes were made. The images or other third party material in this article are included in the article's Creative Commons licence, unless indicated otherwise in a credit line to the material. If material is not included in the article's Creative Commons licence and your intended use is not permitted by statutory regulation or exceeds the permitted use, you will need to obtain permission directly from the copyright holder. To view a copy of this licence, visit http://creativecommons.org/licenses/by/4.0/.

\section{References}

1. Hashimoto S, Fischer-Kowalski M, Sangwon M, Xuemei B (2012) Greening growing giants: a major challenge of our planet. J Ind Ecol 16:459-466. https://doi.org/10.1111/j.1530-9290.2012.00522.x

2. International Resource Panel (2017) Assessing global resource use. In: A systems approach to resource efficiency and pollution reduction. United Nations Environment Programme, Nairobi

3. Allwood JM, Ashby MF, Gutowski TG, Worrell E (2011) Material efficiency: a white paper. Resour Conserv Recycl 55(3):362-381

4. Milios L (2018) Advancing to a circular economy: three essential ingredients for a comprehensive policy mix. Sustain Sci 13(3):861-878

5. European Commission (2019) Communication from the Commission to the European Parliament, the Council, the European Economic and Social Committee and the Committee of the Regions on the European Green Deal. COM(2019) 640. Final. European Commission, Brussels

6. Ghisellini P, Cialani C, Ulgiati S (2016) A review on circular economy: the expected transition to a balanced interplay of environmental and economic systems. J Clean Prod 114:11-32

7. Bruel A, Kronenberg J, Troussier N, Guillaume B (2019) Linking industrial ecology and ecological economics: a theoretical and empirical foundation for the circular economy. J Ind Ecol 23(1):12-21

8. Kirchherr J, Reike D, Hekkert M (2017) Conceptualizing the circular economy: an analysis of 114 definitions. Resour Conserv Recycl 127:221-232

9. Ekvall T, Hirschnitz-Garbers M, Eboli F, Śniegocki A (2016) A systemic and systematic approach to the development of a policy mix for material resource efficiency. Sustainability 8(4):373

10. Wilts H, O’Brien M (2019) A policy mix for resource efficiency in the EU: key instruments, challenges and research needs. Ecol Econ 155:59-69 
11. Mont O, Lindhqvist T (2003) The role of public policy in advancement of product service systems. J Clean Prod 11(8):905-914

12. Hartley K, van Santen R, Kirchherr J (2020) Policies for transitioning towards a circular economy: expectations from the European Union (EU). Resour Conserv Recycl 155:104634

13. Ekins P, Pollitt H, Summerton P, Chewpreecha U (2012) Increasing carbon and material productivity through environmental tax reform. Energ Policy 42:65-376

14. Milne JE, Andersen MS (2012) Handbook of research on environmental taxation. Edward Elgar Publishing, Cheltenham

15. Andersen MS, Elliot T, Sherrington C, Vergunst T, Ettlinger S, Elliot L, Hudson J (2014) Study on environmental fiscal reform potential in 12 EU Member States. Final Report for the European Commission. Eunomia Research and Consulting Ltd., Brussels

16. Palmer K, Walls M (1999) Extended product responsibility: an economic assessment of alternative policies. Resources for the Future, Washington DC

17. Söderholm P (2011) Taxing virgin natural resources: lessons from aggregates taxation in Europe. Resour Conserv Recycl 55(11):911-922

18. Domenech T, Bahn-Walkowiak B (2019) Transition towards a resource efficient circular economy in Europe: policy lessons from the EU and the Member States. Ecol Econ 155:7-19

19. Milios L (2020) Policy framework for material resource efficiency: pathway towards a circular economy. Dissertation. Lund University, Lund

20. Eckermann F, Golde M, Herczeg M, Mazzanti M, Zoboli R, Speck S (2015) Material resource taxation - an analysis for selected material resources. In: European Topic Centre on Sustainable Consumption and Production \& European Topic Centre on Waste and Materials in a Green Economy, Copenhagen

21. Söderholm P, Tilton JE (2012) Material efficiency: an economic perspective. Resour Conserv Recycl 61: 75-82

22. Radetzki M (2008) A handbook of primary commodities in the global economy. Cambridge University Press, Cambridge

23. OECD (2015) Taxation of SMEs in OECD and G20 Countries. Tax Policy Studies, No. 23. Organisation for Economic Co-operation and Development, Paris

24. Rizos V, Behrens A, van der Gaast W, Hofman E, Ioannou A, Kafyeke T, Flamos A, Rinaldi R, Papadelis S, Hirschnitz-Garbers M, Topi C (2016) Implementation of circular economy business models by small and medium-sized enterprises (SMEs): barriers and enablers. Sustainability 8(11):1212

25. International Resource Panel (2018) Re-defining value - the manufacturing revolution. Remanufacturing, refurbishment. In: repair and direct reuse in the circular economy. United Nations Environment Programme, Nairobi

26. Cooper RD, Gutowski TG (2017) The environmental impacts of reuse: a review. J Ind Ecol 21:38-56

27. Copenhagen Economics (2007) Study on reduced VAT applied to goods and services in the Member States of the European Union. European Commission, Brussels

28. SOU (2017) Från värdekedja till värdecykel - så får Sverige en mer cirkulär ekonomi. In: SOU 2017:22. Statens offentliga utredningar, Stockholm

29. Almén J, Anehagen M, Enström E, Hartman C, Jonsson C, Lindbladh F, Ohlsson J, Dalhammar C (2020) In: Richter JL (ed) Promoting the repair sector in Sweden. The International Institute for Industrial Environmental Economics, Lund

30. Eichner T (2005) Imperfect competition in the recycling industry. Metroeconomica 56(1):1-24

31. EEA (2013) Managing municipal solid waste - a review of achievements in 32 European countries. In: Report No 2/2013. European Environment Agency, Copenhagen

32. SOU (2017) Brännheta skatter! Bör avfallsförbränning och utsläpp av kväveoxider från energiproduktion beskattas? In: SOU 2017:83. Statens offentliga utredningar, Stockholm

33. Milios L, Dalhammar C (2020) Ascending the waste hierarchy: re-use potential in Swedish recycling centres. Detritus (9):27-37

34. Lokrantz E (2019) Introducing a new waste hierarchy tax in Sweden: a general equilibrium analysis. Dissertation, Lund University

35. EEA (2016) More from less - material resource efficiency in Europe. In: Country profile: Sweden. European Environment Agency, Copenhagen

36. Sverige A (2020) Swedish Waste Management 2019. Avfall Sverige - Swedish Waste Management Association, Malmö

37. Bryman A (2016) Social Research Methods, 5th edn. Oxford University Press, London

38. Eurostat (2019) National accounts statistics [data set]. https://ec.europa.eu/eurostat/web/national-accounts/ data/database.

39. Eurostat (2019) Waste statistics: treated waste in tonnes [data set]. https://ec.europa.eu/eurostat/web/waste/ data/database. 
40. Schwerhoff G, Franks M (2018) Optimal environmental taxation with capital mobility. Fisc Stud 39(1):39-63

41. Söderholm P, Ekvall T (2019) Metal markets and recycling policies: impacts and challenges. Miner Econ 33:257-272

42. Böhringer C, Rutherford T (2015) The circular economy - an economic impact assessment. https:// sunstiftungsfonds.files.wordpress.com/2015/06/report-circular-economy.pdf.

43. Baptist S, Hepburn C (2013) Intermediate inputs and economic productivity. Philos T Roy Soc A 371(1986)

44. Finnveden G, Ekvall T, Arushanyan Y, Bisaillon M, Henriksson G, Gunnarsson Östling U, Ljunggren Söderman M, Sahlin J, Stenmark Å, Sundberg J, Sundqvist J-O, Svenfelt Å, Söderholm P, Björklund A, Eriksson O, Forsfält T, Guath M (2013) Policy instruments towards a sustainable waste management. Sustainability 5(3):841

45. Ekvall T, Sundqvist J-O, Hemström K, Jensen C (2014) Stakeholder analysis of incineration tax, raw material tax, and weight based waste fee. IVL Report C74. Swedish Environmental Research Institute, Stockholm

46. Andersen MS (2007) An introductory note on the environmental economics of the circular economy. Sustain Sci 2(1):133-140

47. Stahel WR (2013) Policy for material efficiency - sustainable taxation as a departure from the throwaway society. Philos T Roy Soc A 371(1986)

48. Watson D, Gylling AC, Tojo N, Throne-Holst H, Bauer B, Milios L (2017) Circular business models in the mobile phone industry. TemaNord No. 2017:560. Nordic Council of Ministers, Copenhagen

49. Gåvertsson I, Milios L, Dalhammar C (2020) Quality labelling for re-used ICT equipment to support consumer choice in the circular economy. J Consum Policy 43:353-377

50. Maitre-Ekern E, Dalhammar C (2016) Regulating planned obsolescence: a review of legal approaches to increase product durability and reparability in Europe. RECIEL 25(3):378-394

51. Sjöström M, Östblom G (2010) Decoupling waste generation from economic growth — a CGE analysis of the Swedish case. Ecol Econ 69(7):1545-1552

52. Hassler J, Krusell P (2018) Environmental macroeconomics: the case of climate change. http://hassler-j.iies. su.se/PAPERS/Handbook.pdf.

53. Tietenberg TH (1973) Specific taxes and the control of pollution: a general equilibrium analysis. Q J Econ 87(4):503-522

54. King M, Tarbush B, Teytelboym A (2018) Targeted carbon tax reforms. Working paper SSRN. https://doi. org/10.2139/ssrn.3120330.

55. Xie J, Saltzman S (2000) Environmental policy analysis: an environmental computable general-equilibrium approach for developing countries. J Policy Model 22(4):453-489

56. Zink T, Geyer R (2017) Circular economy rebound. J Ind Ecol 21(3):593-602

57. Barrage L (2020) Optimal dynamic carbon taxes in a climate-economy model with distortionary fiscal policy. Rev Econ Stud 87(1):1-39

58. Reike D, Vermeulen WJV, Witjes S (2018) The circular economy: new or refurbished as CE 3.0? exploring controversies in the conceptualization of the circular economy through a focus on history and resource value retention options. Resour Conserv Recycl 135:246-264

59. Gunningham N, Grabosky PN, Sinclair D (1998) Smart regulation: designing environmental policy. Clarendon Press, Oxford

60. Sterner T, Coria J (2011) Policy instruments for environmental and natural resource management. RFF Press, London

61. European Commission (2020) A new circular economy action plan - for a cleaner and more competitive Europe, COM(2020) 98 final. European Commission, Brussels 